\title{
Efeitos da Faixa de Controle do Capim-Braquiária (Brachiaria decumbens) no Desenvolvimento Inicial de Plantas de Eucalipto ${ }^{1}$
}

\author{
Effects of Brachiaria decumbens Strip Control on Eucalypt Initial Plants Development
}

\begin{abstract}
TOledo, R.E.B. ${ }^{2}$, VICTÓRIA FILHO, R. ${ }^{3}$, ALVES, P. L.C.A. ${ }^{4}$, PITElli, R.A. ${ }^{5}$ e CADINI, M.T.D. ${ }^{6}$
RESUMO - Esta pesquisa foi conduzida em área reflorestada com Eucalyptus grandis $\mathrm{x}$ Eucalyptus urophylla, no município de Três Lagoas, MS, no período de julho de 1996 a agosto de 1997, com o objetivo de avaliar os efeitos da variação da faixa de controle de Brachiaria decumbens ao longo da linha de plantio sobre o desenvolvimento inicial de clones de eucalipto. Os tratamentos experimentais constaram de dois grupos: no primeiro foram mantidas faixas constantes de controle durante os 12 meses iniciais após o transplante das mudas no campo: 0, 25, 50, 100, 125 e $150 \mathrm{~cm}$ de cada lado da linha de transplante das mudas de eucalipto; e, no segundo, foram adotadas faixas crescentes de controle ao longo do período experimental. Ao final do período experimental (390 dias após o transplante), constatou-se que as plantas de eucalipto que cresceram nas parcelas com faixas de controle constantes ou crescentes, iguais ou superiores a $100 \mathrm{~cm}$, mostraram-se superiores, em diâmetro, altura e velocidade de crescimento absoluto. Com base nesses resultados, pode-se concluir que a largura mínima da faixa de controle a ser utilizada é de $100 \mathrm{~cm}$ de cada lado da linha, a fim de manter as plantas de eucalipto livres da interferência das plantas daninhas.
\end{abstract}

Palavras-chave: Brachiaria decumbens, reflorestamento, plantas daninhas, interferência, controle.

\begin{abstract}
A field trial was conducted in an area of Eucalyptus grandis $x$ Eucalyptus urophylla at Três Lagoas, Mato Grosso do Sul, Brazil, from July 1996 to December 1997, to evaluate the effects of Brachiaria decumbens control strip variations on the initial development of eucalypt clones. The experiment consisted of two treatment groups: group 01 - with constant width control strips being kept during the first 12 months, i.e., at 0, 25, 50, 100, 125 and $150 \mathrm{~cm}$ on each side of the eucalypt row and, group 02: with increasing width control strips being adopted along the experimental period. At the end of the experimental period (390 days after transplanting), it was verified that the eucalypt plants that had grown both in the constant and increasing width control strips, equal to or higher than $100 \mathrm{~cm}$, showed higher diameter, height and absolute growth in diameter and height. These results led to the conclusion that the control strip's minimum width should be $100 \mathrm{~cm}$ on each side of the eucalypt row in order to keep it free from weed interference.
\end{abstract}

Key words: Brachiaria decumbens, reforestation, weed, interference, control.

\section{INTRODUÇÃO}

Atualmente, o setor florestal ocupa $6 \mathrm{mi}-$ lhões de hectares no Brasil, com plantio de
400 mil hectares ao ano, gera em todo o País cerca de 1,2 milhão de empregos diretos, produz $4 \%$ do PIB nacional, fatura em torno de 15 bilhões de dólares por ano e exporta

\footnotetext{
Recebido para publicação em 10/9/1999 e na forma revisada em 15/12/1999.

2 Eng.-Agro. M.S., Pós-graduando do curso de Fitotecnia da ESALQ/USP, bolsista da CAPES. Dep. de Horticultura, $13400-900$ Piracicaba-SP; ${ }^{3}$ Prof. Titular do Dep. de Horticultura da ESALQ/USP. ${ }^{4}$ Prof. Dr. do Dep. de Biologia Aplicada à Agropecuária da FCAVJ/UNESP, 14.870-000 Jaboticabal-SP; ${ }^{5}$ Prof. Titular do Dep. de Biologia Aplicada à Agropecuária da FCAVJ/UNESP. ${ }^{6}$ Engenheiro Florestal da Champion Papel e Celulose Ltda., 13840.970 Mogi Guaçu-SP.
} 
anualmente 2 bilhões de dólares. Apesar dessa magnitude, deve-se salientar que, para garantir sua sustentabilidade e competitividade, o setor depende, dentre outros fatores, de uma base florestal que atenda a padrões cada vez mais exigentes em termos de qualidade e produtividade, o que conduz ao efetivo investimento em pesquisa e adoção de práticas silviculturais adequadas (Brito, 1995).

Nas últimas décadas, os cientistas das plantas daninhas vêm estudando os efeitos da interferência destas plantas sobre o crescimento e a produtividade das espécies dos gêneros Eucalyptus e Pinus. Dentre os efeitos da interferência, podem-se destacar a competição por água, luz e nutrientes e o fato de elas exercerem interferência de natureza alelopática, atuarem como hospedeiras intermediárias de pragas e patógenos e aumentarem riscos de incêndios. Além desses fatores, depara-se também com o aumento progressivo nos custos da mão-deobra necessária para as operações de limpeza e manutenção desses plantios (IPEF, 1976). Segundo Pitelli \& Marchi (1991), a interferência imposta pelas plantas daninhas é mais severa principalmente na fase inicial de crescimento, ou seja, do transplante até cerca de um ano de idade das plantas de eucalipto.

As plantas daninhas são consideradas o maior problema mundial em termos de pestes agrícolas; apenas nos Estados Unidos, seu custo anual é estimado em 16 bilhões de dólares, considerando-se as perdas de produção e os custos envolvidos no controle. Esta importância aumenta aproximadamente para 21 bilhões de dólares quando se incluem os custos com plantas daninhas em pastagens, florestas e ecossistemas aquáticos (Charudattan, 1993).

É importante ressaltar que o setor florestal tem se expandido em áreas de cerrado anteriormente ocupadas com pastagens, especialmente de Brachiaria decumbens. Assim, esta planta, devido à sua elevada agressividade e ao seu difícil controle, tornou-se uma das infestantes mais problemáticas nos plantios comerciais de Eucalyptus (Toledo, 1994).

O manejo das plantas daninhas em reflorestamentos, nas diversas etapas do seu processo produtivo, é realizado, basicamente, pelo emprego de métodos mecânicos e químicos, isolados ou combinados. Dentre os herbicidas utilizados em áreas de reflorestamento, destacam-se principalmente o oxyfluorfen e o glyphosate, sendo este último utilizado em grande escala, pelo fato de ser usado em pósemergência das plantas daninhas, facilitando a operação em áreas de cultivo mínimo (Toledo, 1998).

De acordo com Stape (1990), uma série de operações silviculturais, como preparo do solo, fertilizações corretivas ou de manutenção e capinas, pode influenciar positiva ou negativamente a produtividade florestal, se não se atentar para a dinâmica do crescimento radicular de plantas de Eucalyptus.

Nesse contexto, este trabalho teve por objetivo estudar o efeito da variação na largura da faixa de controle de Brachiaria decumbens na formação de florestas homogêneas de Eucalyptus grandis x Eucalyptus urophylla, no município de Três Lagoas-MS.

\section{MATERIAL E MÉTODOS}

O experimento foi conduzido em área experimental pertencente à Champion Papel e Celulose Ltda., localizada no município de Três Lagoas, MS, no período de julho de 1996 a agosto de 1997.

A área experimental foi selecionada quanto à sua uniformidade na infestação de Brachiaria decumbens, sendo esta representativa das áreas de produção da empresa florestal. A área era anteriormente cultivada com pastagens. Em levantamento prévio, pela técnica de amostragens aleatórias (Matteucci e Colma, 1982), foi constatado que as espécies mais freqüentes e dominantes eram, além do capim-braquiária (B. decumbens), a erva-quente (Spermacocea latifola) e algumas rebrotas típicas de cerrado.

Após a escolha, a área foi preparada para o transplante das mudas de eucalipto. Inicialmente, foi efetuada a derrubada de árvores esparsas e procedeu-se à passagem de uma gradagem dupla com máquina pesada e de uma gradagem média em área total. Em seguida, foram realizadas a abertura dos sulcos e a adubação de transplante, a qual se constituiu na distribuição, ao longo do sulco, do adubo NPK na fórmula 08-32-16 + micronutrientes (0,3\% Zn, 0,07\% Cu e 0,5\% B), em quantidade equivalente a $140 \mathrm{~kg} \mathrm{ha}^{-1}$. 
As mudas de eucalipto, clones provenientes de micropropagação obtidos no viveiro da Champion Papel e Celulose Ltda., e um híbrido resultante do cruzamento entre $E$. grandis e E. urophylla muito utilizado atualmente pelas empresas florestais em razão de seu rápido crescimento, associado à sua tolerância a períodos mais longos de veranico, com cerca de 100 dias de idade, foram plantados obedecendo a um espaçamento de $3,0 \mathrm{~m}$ entre plantas e 3,0 $\mathrm{m}$ na entrelinha de transplante.

As parcelas experimentais foram constituídas por seis linhas de plantio com oito plantas cada, totalizando $432 \mathrm{~m}^{2}$, sendo duas linhas externas de cada lado e duas plantas nas extremidades da linha consideradas como bordadura, totalizando $72,0 \mathrm{~m}^{2}$ de área útil. O experimento foi conduzido em um Latossolo Vermelho-Escuro, textura média e álico.

A variável experimental constou de diferentes extensões da largura da faixa de controle do capim-braquiária de cada lado da linha de transplante das mudas de eucalipto. Os tratamentos experimentais constaram de dois grupos: no primeiro foram mantidas faixas constantes de controle durante os 12 meses iniciais, a saber: $0,25,50,100,125$ e $150 \mathrm{~cm}$ de cada lado da linha de transplante; e, no segundo, foram adotadas faixas crescentes de controle, no decorrer do período experimental, de acordo com estudo sobre o crescimento radicular do eucalipto realizado por Stape (1990).

No campo, os tratamentos relacionados na Tabela 1 foram dispostos no delineamento experimental de blocos ao acaso, em quatro repetições, sendo os dados obtidos submetidos ao teste $\mathrm{F}$ aplicado à análise de variância e as médias confrontadas pelo teste de comparação múltipla de Tukey a $1 \%$ de probabilidade. Para a prova da existência de diferentes grupos de tratamentos, foi utilizado o desdobramento dos graus de liberdade de tratamentos em contrastes ortogonais de interesse, descritos na Tabela 2.

As faixas de controle do capim-braquiária, com o objetivo de manter as plantas de eucalipto livres da interferência dessa planta daninha, foram feitas por meio de capina manual, utilizando-se de um sistema de balizamento com estacas para facilitar a operação e permitir a correta execução das diferentes faixas de controle.

Aos 210, 240, 270, 300, 330, 360 e 390 dias após o transplante (DAT) das mudas, as oito plantas úteis de eucalipto foram avaliadas quanto ao diâmetro do caule e à altura.

Tabela 1 - Variações da largura da faixa de controle de Brachiaria decumbens durante os meses de agosto a julho, nos tratamentos avaliados, em cultura de eucalipto. Três Lagoas-MS. 1997

\begin{tabular}{|c|r|r|r|r|r|r|r|r|r|r|r|r|}
\hline \multicolumn{10}{|c|}{ Tratamentos Experimentais } \\
\hline \begin{tabular}{c}
\hline \multicolumn{10}{|c|}{ Faixas de } \\
Capina
\end{tabular} & A & S & O & N & D & J & F & M & A & M & J & J \\
\hline T1 & 0 & 0 & 0 & 0 & 0 & 0 & 0 & 0 & 0 & 0 & 0 & 0 \\
T2 & 25 & 25 & 25 & 25 & 25 & 25 & 25 & 25 & 25 & 25 & 25 & 25 \\
T3 & 50 & 50 & 50 & 50 & 50 & 50 & 50 & 50 & 50 & 50 & 50 & 50 \\
T4 & 100 & 100 & 100 & 100 & 100 & 100 & 100 & 100 & 100 & 100 & 100 & 100 \\
T5 & 125 & 125 & 125 & 125 & 125 & 125 & 125 & 125 & 125 & 125 & 125 & 125 \\
T6 & 150 & 150 & 150 & 150 & 150 & 150 & 150 & 150 & 150 & 150 & 150 & 150 \\
T7 & 25 & 50 & 100 & 125 & 150 & 150 & 150 & 150 & 150 & 150 & 150 & 150 \\
T8 & 25 & 50 & 50 & 100 & 125 & 150 & 150 & 150 & 150 & 150 & 150 & 150 \\
T9 & 50 & 50 & 100 & 125 & 150 & 150 & 150 & 150 & 150 & 150 & 150 & 150 \\
T10 & 50 & 50 & 50 & 125 & 125 & 150 & 150 & 150 & 150 & 150 & 150 & 150 \\
T11 & 100 & 100 & 100 & 125 & 150 & 150 & 150 & 150 & 150 & 150 & 150 & 150 \\
T12 & 100 & 100 & 100 & 100 & 150 & 150 & 150 & 150 & 150 & 150 & 150 & 150 \\
T13 & 125 & 125 & 125 & 125 & 150 & 150 & 150 & 150 & 150 & 150 & 150 & 150 \\
\hline
\end{tabular}


Tabela 2 - Descrição dos contrastes ortogonais de interesse, utilizados no ensaio de efeitos da variação da faixa de controle do capim-braquiária. Três Lagoas-MS. 1997

\begin{tabular}{|c|c|}
\hline Controle & Descrição \\
\hline $\mathrm{Y}(1)$ & $\begin{array}{l}\text { Faixas constantes } \times \text { Faixas crescentes } \\
(\mathrm{T} 1 \text { a T6) } \times(\mathrm{T} 7 \text { a T13) }\end{array}$ \\
\hline$Y(2)$ & $\begin{array}{l}\text { Faixas constantes de } 0 \text { a } 50 \mathrm{~cm} \text { X Faixas } \\
\text { constantes de } 100 \text { a } 150 \mathrm{~cm} \\
(\mathrm{~T} 1+\mathrm{T} 2+\mathrm{T} 3) \times(\mathrm{T} 4+\mathrm{T} 5+\mathrm{T} 6)\end{array}$ \\
\hline$Y(3)$ & $\begin{array}{l}\text { Testemunha sem controle X Tratamento-padrão da } \\
\text { empresa (faixa } 50 \mathrm{~cm}) \\
(\mathrm{T} 1) \times(\mathrm{T} 3)\end{array}$ \\
\hline $\mathrm{Y}(4)$ & $\begin{array}{l}\text { Faixa constante de } 100 \mathrm{~cm} \mathrm{X} \mathrm{Testemunha} \mathrm{no} \mathrm{limpo} \\
(150 \mathrm{~cm}) \\
(\mathrm{T} 4) \times(\mathrm{T} 6)\end{array}$ \\
\hline$Y(5)$ & $\begin{array}{l}\text { Faixas crescentes que iniciaram com } 25 \text { e } 50 \mathrm{~cm} \mathrm{x} \\
\text { Faixas crescentes que iniciaram com } 100 \text { a } 150 \mathrm{~cm} \\
(\mathrm{~T} 7+\mathrm{T} 8+\mathrm{T} 9+\mathrm{T} 10) \times(\mathrm{T} 11+\mathrm{T} 12+\mathrm{T} 13)\end{array}$ \\
\hline$Y(6)$ & $\begin{array}{l}\text { Faixas constantes de } 100 \mathrm{~cm} \text { até os } 3 \text { meses } \\
\text { iniciais } \times \text { Faixas constantes de } 125 \mathrm{~cm} \text { até os } 3 \\
\text { meses iniciais } \\
\text { (T11) X (T13) }\end{array}$ \\
\hline
\end{tabular}

Com base nos dados de altura e diâmetro do caule das plantas úteis de eucalipto, foram calculadas as taxas de crescimento absoluto em altura $\left(\mathrm{TCA}_{\mathrm{H}}\right)$ e diâmetro (TCA $\varnothing$ ), segundo as fórmulas propostas por Benincasa (1988):

$T C A_{H}=\left(H_{2}-H_{1}\right) /\left(T_{2}-T_{1}\right)(\mathrm{cm} /$ dia), em que $\boldsymbol{H}_{2}$ e $\boldsymbol{H}_{1}$ correspondem a altura das plantas de eucalipto de duas avaliações sucessivas nos tempos $\boldsymbol{T}_{2}$ e $\boldsymbol{T}_{1}$, respectivamente.

$\operatorname{TCA} \varnothing=\left(\varnothing_{2}-\varnothing_{1}\right) /\left(T_{2}-T_{1}\right)(\mathrm{cm} /$ dia $)$, em que $\varnothing_{2}$ e $\varnothing_{1}$ correspondem ao diâmetro do caule das plantas de eucalipto de duas avaliações sucessivas nos tempos $\boldsymbol{T}_{2}$ e $\boldsymbol{T}_{1}$, respectivamente.

Na área útil de cada parcela experimental foi amostrado $1,5 \mathrm{~m}^{2}$, correspondendo a seis subamostras de $0,25 \mathrm{~m}^{2}$, das quais três foram realizadas na linha e três na entrelinha de transplante da cultura. As espécies de plantas daninhas presentes foram identificadas, contadas e levadas ao laboratório do Departamento de Biologia Aplicada à Agropecuária da Faculdade de Ciências Agrárias e Veterinárias de Jaboticabal, UNESP, onde foram lavadas e secas em estufa com renovação forçada de ar a $70{ }^{\circ} \mathrm{C}$ por 96 horas. Após este procedimento, foi determinada a biomassa seca da parte aérea das plantas coletadas, utilizando balança eletrônica com precisão de 0,01 g.

Planta Daninha, Viçosa-MG, v.18, n.3, p.383-393, 2000

\section{RESULTADOS E DISCUSSÃO}

As principais espécies de plantas daninhas presentes na área experimental foram o capimbraquiária (Brachiaria decumbens) e a ervaquente (Spermacocea latifola). O capimbraquiária foi a população predominante, correspondendo, em média, a $241 \mathrm{~g} \mathrm{~m}^{-2}$ (89\%) da biomassa seca acumulada na área total da parcela da testemunha "no mato", distribuída da seguinte forma: $98 \mathrm{~g} \mathrm{~m}^{-2}$ na linha (96\%) e $143 \mathrm{~g} \mathrm{~m}^{-2}$ (81\%) na entrelinha de transplante do eucalipto. Por outro lado, a erva-quente correspondeu em média a $38 \mathrm{~g} \mathrm{~m}^{-2}$ (11\%), sendo $4 \mathrm{~g} \mathrm{~m}^{-2}(4 \%)$ na linha e $34 \mathrm{~g} \mathrm{~m}^{-2}(18 \%)$ na entre linha de transplante. Nas Figuras 1 e 2, podese observar que, nos meses de dezembro de 1996 e março de 1997, foram obtidos os maiores valores de biomassa seca acumulada pelas populações do capim-braquiária $\left(600 \mathrm{~g} \mathrm{~m}^{-2}\right) \mathrm{e}$ da erva-quente ( $180 \mathrm{~g} \mathrm{~m}^{-2}$ ), o que pode ser devido ao elevado índice pluvial (Figura 3).

A densidade média do capim-braquiária observada durante o período experimental foi de 27 plantas $/ \mathrm{m}^{2}$ na área total das parcelas, divididas em 8 plantas $/ \mathrm{m}^{2}$ na linha e 9 plantas $/ \mathrm{m}^{2}$ na entrelinha de transplante do eucalipto (Figura 4). A densidade da erva-quente foi de 6 plantas $/ \mathrm{m}^{2}$, com 4 plantas $/ \mathrm{m}^{2}$ na linha e 2 plantas $/ \mathrm{m}^{2}$ na entrelinha da cultura, conforme pode ser observado na Figura 5.

Bezutte et al. (1995) observaram que, a partir de 4 plantas $/ \mathrm{m}^{2}$, o capim-braquiária interfere significativamente no crescimento inicial das mudas de eucalipto, reduzindo em média $28 \%$ o diâmetro e $18 \%$ a altura das plantas, aos 190 DAT. Portanto, a densidade média das duas espécies de plantas daninhas observada na presente pesquisa, ou seja, 16,5 plantas $/ \mathrm{m}^{2}$, justifica a necessidade de controle das plantas daninhas.

No decorrer do período experimental, quando se chegou a utilizar seis capinas em diferentes larguras de faixas, não se observou qualquer sintoma de injúria nas plantas de eucalipto que pudesse ser atribuído aos tratamentos.

Em relação às faixas de controle adotadas, constatou-se que a faixa de $150 \mathrm{~cm}$, de cada lado da linha de transplante, no caso a testemunha "no limpo", foi aquela em que se obteve 
melhor eficácia no controle do capim-braquiária, pelo fato de terem sido necessárias quatro capinas ao longo do período experimental, enquanto nos demais tratamentos foram necessárias, em média, seis capinas.

Pelo desdobramento dos graus de liberdade de tratamentos em contrastes ortogonais de interesse, descritos na Tabela 2, pode-se comprovar a existência de dois diferentes grupos de tratamentos, constituídos por dois subgrupos cada, a saber: grupo I (subgrupo $\mathrm{A}=\mathrm{T} 1$, T2 e T3; subgrupo B = T4, T5 e T6) e grupo II (subgrupo $\mathrm{C}=\mathrm{T} 7, \mathrm{~T} 8$, T9 e $\mathrm{T} 10$; subgrupo $\mathrm{D}=$ T11, T12 e T13).

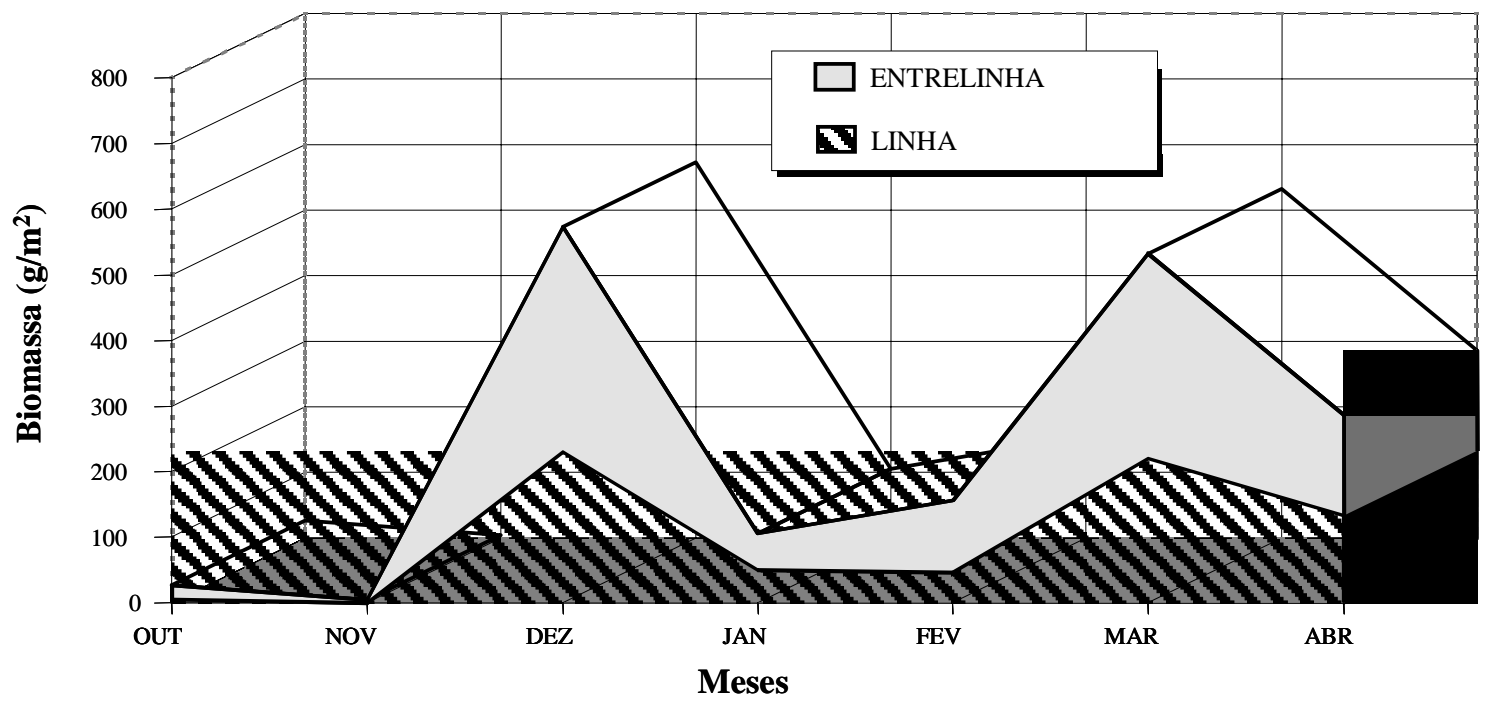

Figura 1 - Biomassa acumulada do capim-braquiária durante o período de outubro de 1996 a abril de 1997. Três Lagoas-MS.

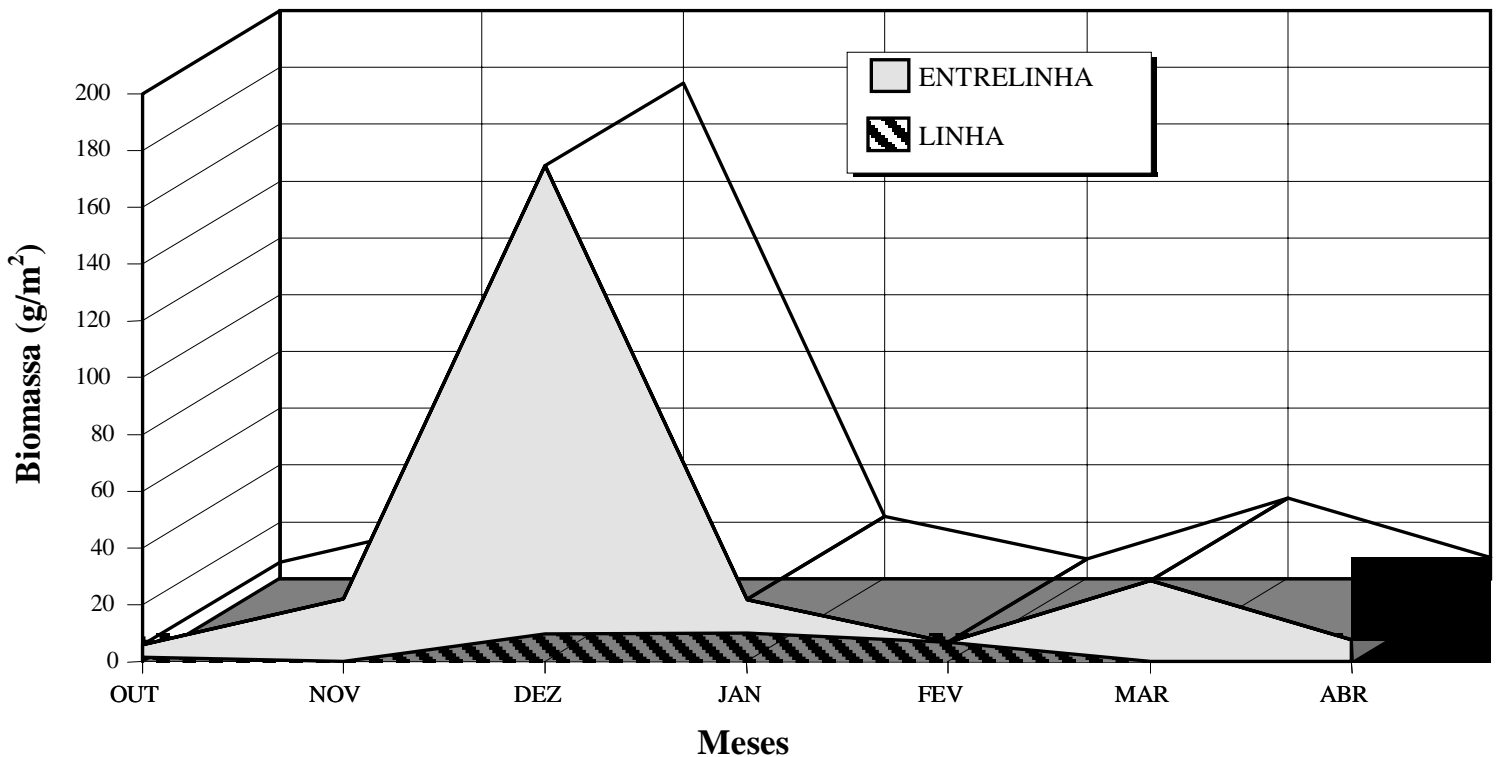

Figura 2 - Biomassa acumulada de erva-quente durante o período de outubro de 1996 a abril de 1997. Três Lagoas-MS. 


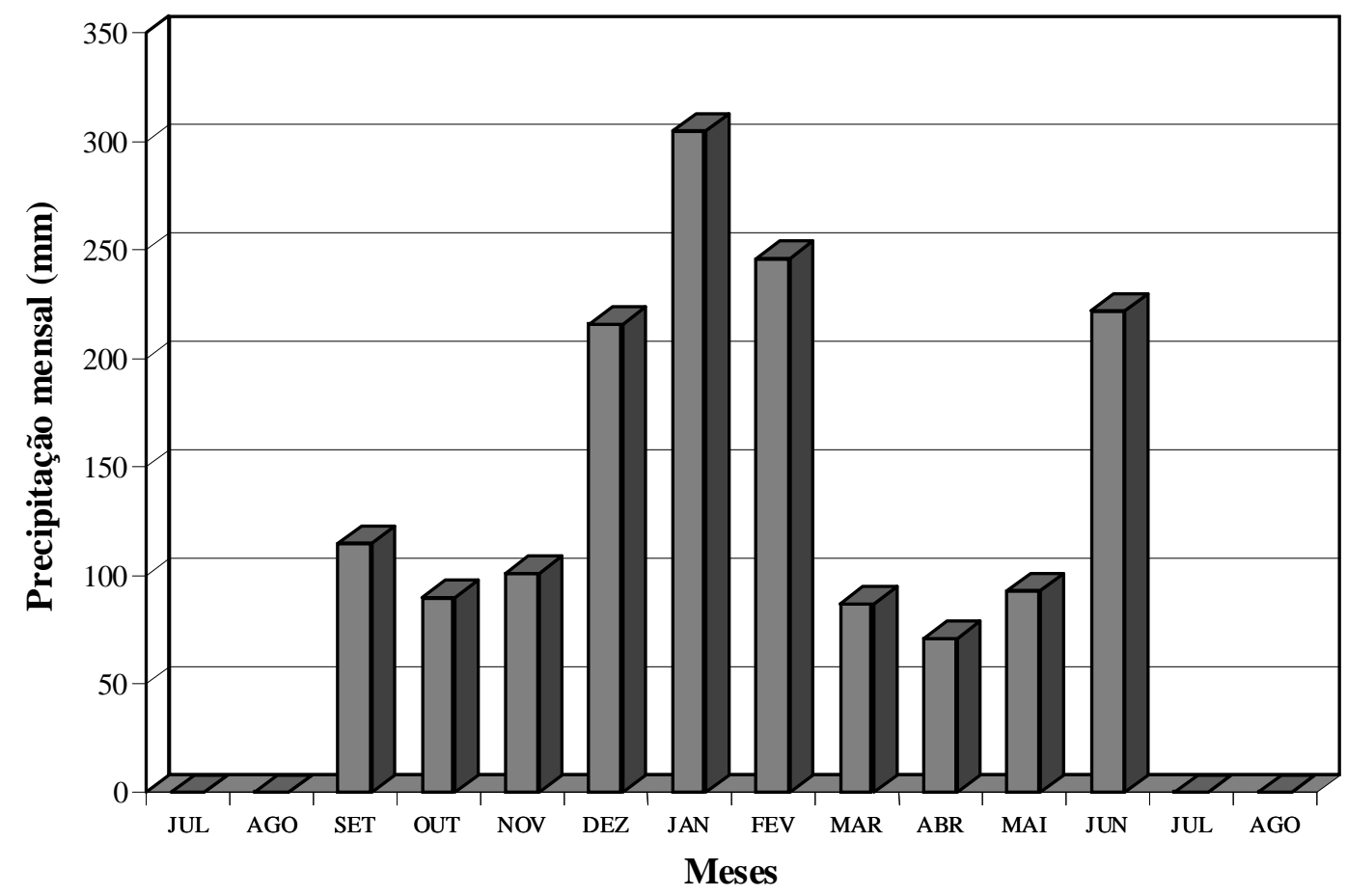

Figura 3 - Precipitação pluvial mensal na área experimental. Três Lagoas-MS. 1996/1997.

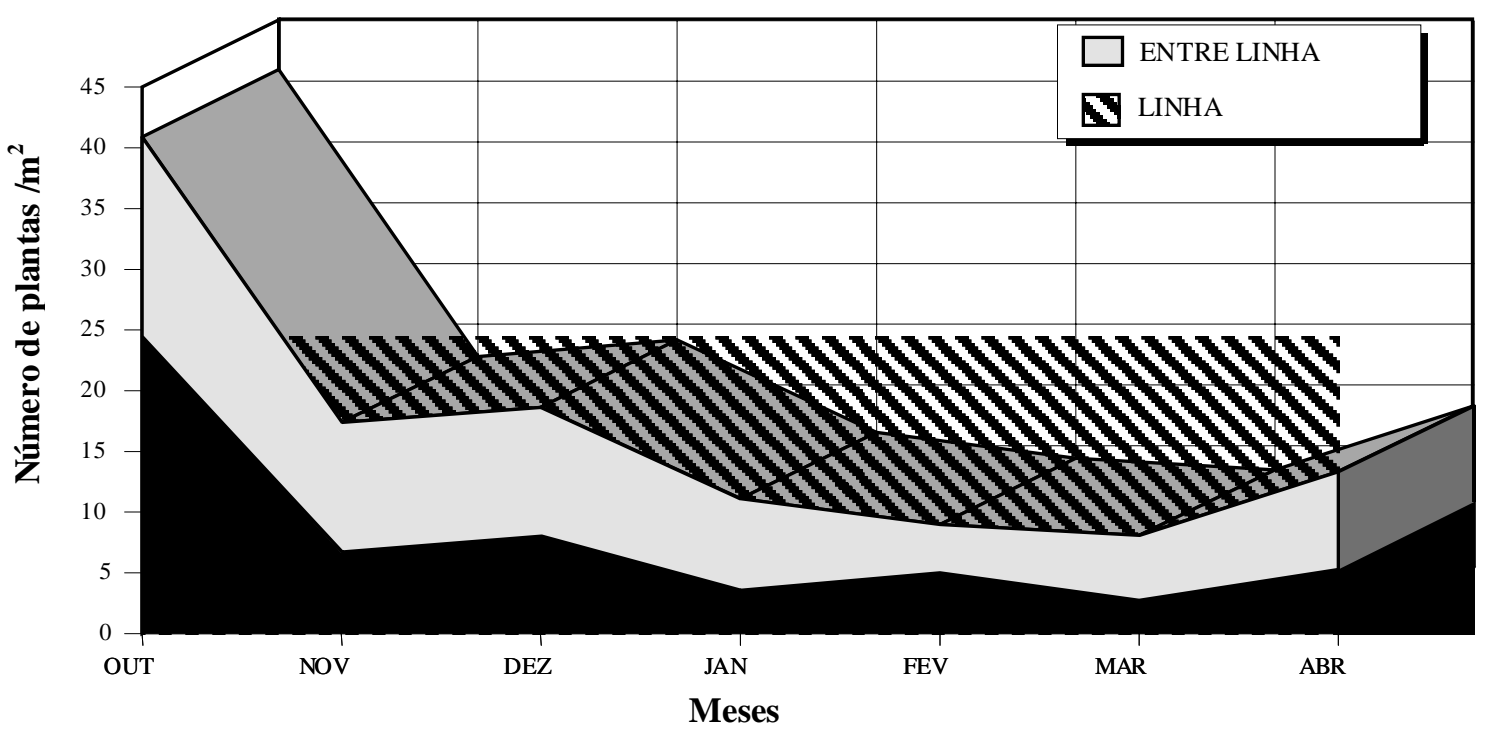

Figura 4 - Densidade do capim-braquiária durante o período de outubro de 1996 a abril de 1997. Três Lagoas-MS.

Ao término do período experimental (390 DAT), foi possivel aferir, pelo contraste $Y(1)$, que as plantas de eucalipto que cresceram nas parcelas dos tratamentos de faixa constante de controle (T1 a T6) apresentaram diâmetro do caule e altura das plantas de eucalipto diferentes das que cresceram nas parcelas dos tratamentos nos quais as faixas de controle foram crescentes (Tabelas 3 e 4). Todavia, observa-se, pelas Tabelas 5 e 6, que os tratamentos $\mathrm{T} 4$ a $\mathrm{T} 6$ e $\mathrm{T} 11$ a T13 apresentaram os maiores valores para diâmetro de caule e altura 
das plantas, respectivamente. Pelo contraste Y (2), foi observado que as plantas de eucalipto que permaneceram livres da interferência do capim-braquiária numa faixa de até $50 \mathrm{~cm}$ de cada lado da linha de transplante (T1 a T3) apresentaram menores diâmetro e altura, a partir dos 240 e até 390 DAT, quando comparadas com as plantas de eucalipto das parcelas nas quais as faixas de controle foram iguais ou superiores a $100 \mathrm{~cm}$ (T4 a T6). Pode-se observar, pelas Tabelas 5 e 6, que os tratamentos T1 a T3 apresentaram diferença significativa em relação aos tratamentos T4 a T6. Já pelo contraste Y (3) foi verificado que as plantas que conviveram com a comunidade infestante (T1) não apresentaram diferença significativa em diâmetro e altura das plantas do tratamento de faixa constante de $50 \mathrm{~cm}$ de cada lado da linha, padrão adotado por diversas empresas florestais (Tabelas $3 \mathrm{e}$ 4). Nas faixas de controle constantes de 100, 125 e $150 \mathrm{~cm}$, foi observado, pelo contraste $Y$ (4), que as plantas de eucalipto não apresentaram diferença significativa entre si, em relação a diâmetro e altura (Tabelas 5 e 6).

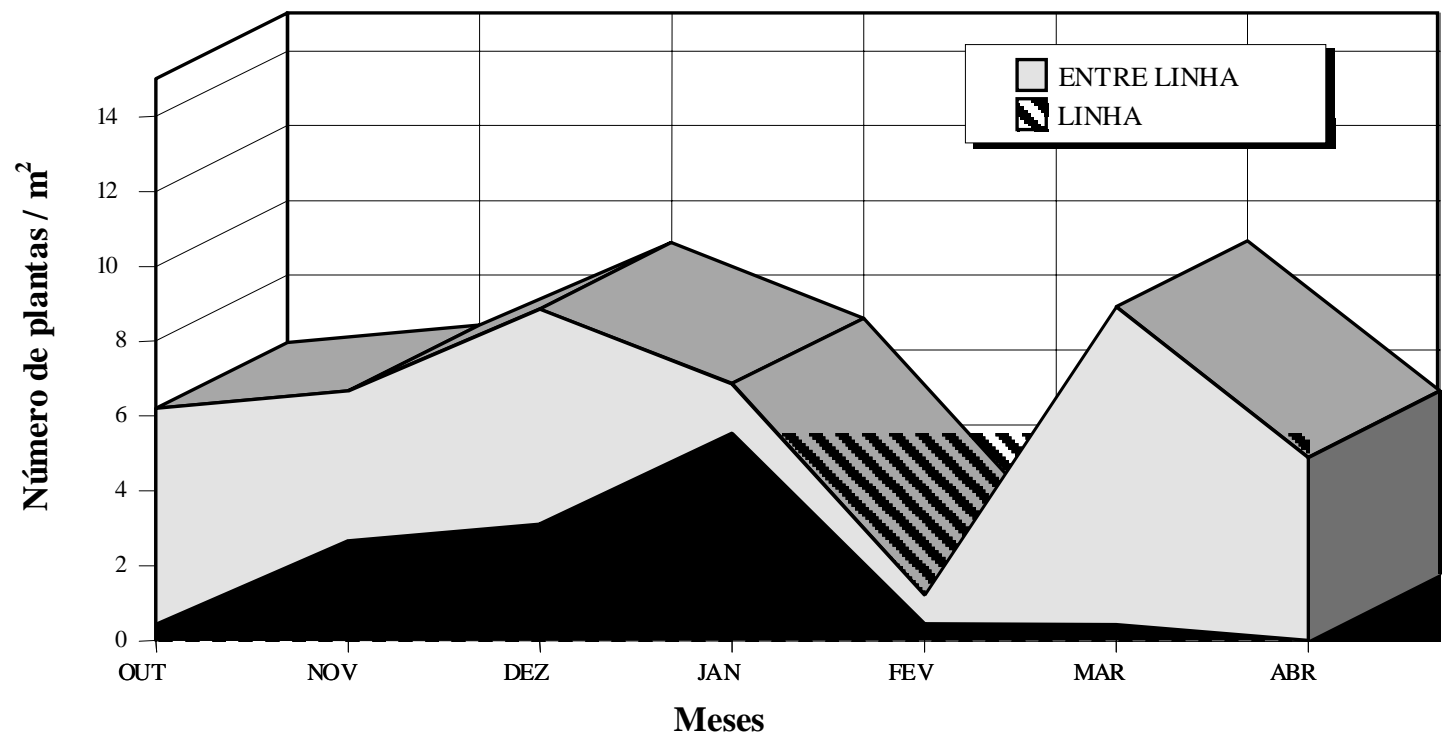

Figura 5 - Densidade de erva-quente durante o período de outubro de 1996 a abril de 1997. Três Lagoas-MS.

Tabela 3 - Valores de F dos contrastes de interesse em relação ao diâmetro de plantas de eucalipto. Três Lagoas-MS. 1996/ 1997

\begin{tabular}{|c|r|r|c|c|c|}
\hline \multirow{2}{*}{ Contraste } & \multicolumn{5}{|c|}{ Dias após o transplante } \\
\cline { 2 - 6 } & 210 & 270 & 300 & 360 & 390 \\
\hline $\mathrm{Y}(1)$ & $0,90 \mathrm{~ns}$ & $4,35 *$ & $16,88 * *$ & $37,54 * *$ & $44,55 * *$ \\
$\mathrm{Y}(2)$ & $11,87 * *$ & $74,80 * *$ & $113,44 * *$ & $155,44 * *$ & $100,82 * *$ \\
$\mathrm{Y}(3)$ & $0,03 \mathrm{~ns}$ & $1,40 \mathrm{~ns}$ & $1,99 \mathrm{~ns}$ & $3,37 \mathrm{~ns}$ & $3,61 \mathrm{~ns}$ \\
$\mathrm{Y}(4)$ & $0,02 \mathrm{~ns}$ & $2,63 \mathrm{~ns}$ & $4,70 *$ & $4,70 *$ & $3,22 \mathrm{~ns}$ \\
$\mathrm{Y}(5)$ & $12,84 * *$ & $19,99 * *$ & $21,84 \mathrm{~ns}$ & $20,25 \mathrm{~ns}$ & $16,32 * *$ \\
$\mathrm{Y}(6)$ & $0,00 \mathrm{~ns}$ & $0,08 \mathrm{~ns}$ & $0,20 \mathrm{~ns}$ & $0,39 \mathrm{~ns}$ & $0,13 \mathrm{~ns}$ \\
\hline
\end{tabular}

ns: não-significativo pelo teste $\mathrm{F}$.

* significativo pelo teste $\mathrm{F}$ a $5 \%$ de probabilidade.

** significativo pelo teste $\mathrm{F}$ a $1 \%$ de probabilidade.
Tabela 4 -Valores de F dos contrastes de interesse em relação à altura de plantas de eucalipto. Três Lagoas-MS. 1996/ 1997

\begin{tabular}{|c|c|c|c|c|c|}
\hline \multirow{2}{*}{ Contraste } & \multicolumn{5}{|c|}{ Dias após o transplante } \\
\cline { 2 - 6 } & 210 & 270 & 300 & 360 & 390 \\
\hline $\mathrm{Y}(1)$ & $0,02 \mathrm{~ns}$ & $0,02 \mathrm{~ns}$ & $2,27 \mathrm{~ns}$ & $15,52 * *$ & $33,02 * *$ \\
$\mathrm{Y}(2)$ & $12,74 * *$ & $91,00 * *$ & $86,67 * *$ & $146,95 * *$ & $94,59 * *$ \\
$\mathrm{Y}(3)$ & $0,54 \mathrm{~ns}$ & $0,33 \mathrm{~ns}$ & $0,47 \mathrm{~ns}$ & $1,06 \mathrm{~ns}$ & $1,57 \mathrm{~ns}$ \\
$\mathrm{Y}(4)$ & $0,23 \mathrm{~ns}$ & $1,89 \mathrm{~ns}$ & $3,76 \mathrm{~ns}$ & $4,31 \mathrm{~ns}$ & $3,67 \mathrm{~ns}$ \\
$\mathrm{Y}(5)$ & $12,59 * *$ & $28,28 \mathrm{~ns}$ & $28,00 * *$ & $23,77 * *$ & $19,15 * *$ \\
$\mathrm{Y}(6)$ & $0,00 \mathrm{~ns}$ & $0,25 \mathrm{~ns}$ & $1,08 \mathrm{~ns}$ & $0,01 \mathrm{~ns}$ & $0,18 \mathrm{~ns}$ \\
\hline
\end{tabular}

ns: não-significativo pelo teste $\mathrm{F}$.

* significativo pelo teste $\mathrm{F}$ a $5 \%$ de probabilidade.

** significativo pelo teste $\mathrm{F}$ a $1 \%$ de probabilidade.

Planta Daninha, Viçosa-MG, v.18, n.3, p.383-393, 2000 
Tabela 5 - Efeito das faixas de controle do capim-braquiária sobre o diâmetro $(\mathrm{cm})$ de plantas de eucalipto. Três Lagoas-MS. $1996 / 1997$

\begin{tabular}{|c|c|c|c|c|c|c|c|}
\hline \multicolumn{8}{|c|}{ Diâmetro $(\mathrm{cm})$} \\
\hline \multicolumn{8}{|c|}{ DAT } \\
\hline Trat & 210 & 240 & 270 & 300 & 330 & 360 & 390 \\
\hline $\mathrm{T} 1$ & $2,96 \mathrm{a}$ & $2,95 \mathrm{~b}$ & $3,16 \mathrm{c}$ & $3,43 \mathrm{~d}$ & $3,54 \mathrm{e}$ & $3,78 \mathrm{e}$ & $3,93 \mathrm{~d}$ \\
\hline $\mathrm{T} 2$ & $2,78 \mathrm{a}$ & $2,96 \mathrm{~b}$ & $3,01 \mathrm{c}$ & $3,16 \mathrm{~d}$ & $3,34 \mathrm{e}$ & $3,59 \mathrm{e}$ & $3,98 \mathrm{~d}$ \\
\hline $\mathrm{T} 3$ & $2,88 \mathrm{a}$ & $3,77 \mathrm{ab}$ & $4,13 \mathrm{bc}$ & $4,54 \mathrm{~cd}$ & $4,70 \mathrm{de}$ & $5,33 \mathrm{~d}$ & $5,68 \mathrm{~cd}$ \\
\hline $\mathrm{T} 4$ & $3,81 \mathrm{a}$ & $4,20 \mathrm{ab}$ & $5,29 a b$ & $5,92 \mathrm{abc}$ & $6,53 \mathrm{abc}$ & $7,03 \mathrm{abc}$ & $7,49 \mathrm{ab}$ \\
\hline T5 & $4,17 \mathrm{a}$ & $4,87 \mathrm{a}$ & $5,22 \mathrm{ab}$ & $6,23 \mathrm{ab}$ & $6,75 \mathrm{abc}$ & $7,46 \mathrm{abc}$ & $7,42 \mathrm{abc}$ \\
\hline T6 & $3,73 \mathrm{a}$ & $4,29 \mathrm{ab}$ & $6,05 \mathrm{a}$ & $6,76 \mathrm{a}$ & $7,38 \mathrm{a}$ & 8,09 a & $8,56 \mathrm{a}$ \\
\hline $\mathrm{T} 7$ & $2,67 \mathrm{a}$ & $2,88 \mathrm{~b}$ & $4,24 \mathrm{bc}$ & $5,07 \mathrm{bc}$ & $5,87 \mathrm{bcd}$ & $6,47 \mathrm{bcd}$ & $6,92 \mathrm{abc}$ \\
\hline $\mathrm{T} 8$ & $3,78 \mathrm{a}$ & $4,00 \mathrm{ab}$ & $4,36 \mathrm{bc}$ & $5,00 \mathrm{bc}$ & $5,87 \mathrm{bcd}$ & $6,42 \mathrm{bcd}$ & $6,90 \mathrm{abc}$ \\
\hline T9 & $2,87 \mathrm{a}$ & $3,41 \mathrm{ab}$ & $4,35 \mathrm{bc}$ & $5,17 \mathrm{bc}$ & $5,93 \mathrm{bcd}$ & $6,63 \mathrm{abcd}$ & $6,96 \mathrm{abc}$ \\
\hline $\mathrm{T} 10$ & $2,76 \mathrm{a}$ & $3,14 \mathrm{ab}$ & $4,13 \mathrm{bc}$ & $5,23 \mathrm{bc}$ & $5,49 \mathrm{~cd}$ & $6,24 \mathrm{~cd}$ & $6,73 \mathrm{bc}$ \\
\hline $\mathrm{T} 11$ & $4,03 \mathrm{a}$ & $4,73 \mathrm{ab}$ & $5,42 \mathrm{ab}$ & $6,16 \mathrm{ab}$ & $6,71 \mathrm{abc}$ & $7,52 \mathrm{abc}$ & $8,14 \mathrm{ab}$ \\
\hline $\mathrm{T} 12$ & $4,02 \mathrm{a}$ & $4,15 \mathrm{ab}$ & $5,44 a b$ & $6,36 \mathrm{ab}$ & $6,92 \mathrm{abc}$ & $7,52 \mathrm{abc}$ & $8,02 \mathrm{a}$ \\
\hline $\mathrm{T} 13$ & $4,01 \mathrm{a}$ & $4,47 \mathrm{ab}$ & $5,29 \mathrm{ab}$ & $6,37 \mathrm{ab}$ & $7,16 \mathrm{ab}$ & $7,83 \mathrm{ab}$ & $8,35 \mathrm{ab}$ \\
\hline $\mathrm{F}$ & $2,64 *$ & $3,84 *$ & $10,10 * *$ & $16,25 * *$ & $20,21 * *$ & $23,26 * *$ & $17,59 * *$ \\
\hline DMS & 1,83 & 1,88 & 1,45 & 1,40 & 1,45 & 1,50 & 1,79 \\
\hline $\mathrm{CV}$ & 21,36 & 19,34 & 12,48 & 10,46 & 9,87 & 9,26 & 10,45 \\
\hline
\end{tabular}

Médias seguidas de mesma letra não diferem significativamente entre si pelo teste de Tukey a 1\% de probabilidade.

* significativo pelo teste $\mathrm{F}$ a $5 \%$ de probabilidade.

** significativo pelo teste $\mathrm{F}$ a $1 \%$ de probabilidade.

Tabela 6 - Efeito das faixas de controle do capim-braquiária sobre a altura (m) de plantas de eucalipto. Três Lagoas-MS. 1996/ 1997

\begin{tabular}{|l|c|c|c|c|c|c|c|}
\hline \multicolumn{7}{|c|}{ Altura $(\mathrm{cm})$} \\
\hline Trat & 210 & 240 & 270 & 300 & 330 & 360 & 390 \\
\hline T1 & $2,37 \mathrm{a}$ & $2,54 \mathrm{ab}$ & $2,66 \mathrm{ef}$ & $2,73 \mathrm{fg}$ & $2,86 \mathrm{gh}$ & $2,99 \mathrm{e}$ & $3,18 \mathrm{gh}$ \\
T2 & $2,14 \mathrm{a}$ & $2,19 \mathrm{~b}$ & $2,41 \mathrm{f}$ & $2,55 \mathrm{~g}$ & $2,68 \mathrm{~h}$ & $2,74 \mathrm{e}$ & $2,84 \mathrm{~h}$ \\
T3 & $2,13 \mathrm{a}$ & $3,22 \mathrm{ab}$ & $3,20 \mathrm{cdef}$ & $3,38 \mathrm{efg}$ & $3,06 \mathrm{fgh}$ & $3,82 \mathrm{de}$ & $4,23 \mathrm{fg}$ \\
T4 & $2,74 \mathrm{a}$ & $3,22 \mathrm{a}$ & $4,26 \mathrm{ab}$ & $4,56 \mathrm{abc}$ & $5,00 \mathrm{abcde}$ & $5,37 \mathrm{abc}$ & $5,81 \mathrm{abcde}$ \\
T5 & $2,97 \mathrm{a}$ & $3,56 \mathrm{a}$ & $4,60 \mathrm{ab}$ & $5,04 \mathrm{a}$ & $5,42 \mathrm{ab}$ & $5,89 \mathrm{a}$ & $6,25 \mathrm{abcd}$ \\
T6 & $2,67 \mathrm{a}$ & $3,13 \mathrm{ab}$ & $4,78 \mathrm{a}$ & $5,40 \mathrm{a}$ & $5,78 \mathrm{a}$ & $6,21 \mathrm{a}$ & $6,74 \mathrm{a}$ \\
\hline T7 & $2,08 \mathrm{a}$ & $2,26 \mathrm{~b}$ & $3,10 \mathrm{def}$ & $3,68 \mathrm{bcdef}$ & $4,22 \mathrm{bcde}$ & $4,68 \mathrm{bcd}$ & $5,33 \mathrm{bcdef}$ \\
T8 & $2,65 \mathrm{a}$ & $3,32 \mathrm{ab}$ & $3,63 \mathrm{bcde}$ & $3,83 \mathrm{bcde}$ & $4,19 \mathrm{cdef}$ & $4,66 \mathrm{bcd}$ & $5,14 \mathrm{cdef}$ \\
T9 & $2,12 \mathrm{a}$ & $2,65 \mathrm{ab}$ & $3,04 \mathrm{def}$ & $3,58 \mathrm{cdefg}$ & $4,08 \mathrm{defg}$ & $4,59 \mathrm{bcd}$ & $5,07 \mathrm{def}$ \\
T10 & $2,16 \mathrm{a}$ & $2,56 \mathrm{ab}$ & $2,93 \mathrm{def}$ & $3,47 \mathrm{defg}$ & $3,93 \mathrm{efg}$ & $4,33 \mathrm{~cd}$ & $4,98 \mathrm{ef}$ \\
T11 & $2,86 \mathrm{a}$ & $3,60 \mathrm{a}$ & $4,24 \mathrm{abc}$ & $4,66 \mathrm{abc}$ & $5,23 \mathrm{abcd}$ & $5,73 \mathrm{ab}$ & $6,48 \mathrm{ab}$ \\
T12 & $2,91 \mathrm{a}$ & $3,11 \mathrm{ab}$ & $3,98 \mathrm{abcd}$ & $4,54 \mathrm{abcd}$ & $5,11 \mathrm{abcde}$ & $5,52 \mathrm{ab}$ & $6,06 \mathrm{abcde}$ \\
T13 & $2,85 \mathrm{a}$ & $3,35 \mathrm{ab}$ & $4,18 \mathrm{abc}$ & $4,71 \mathrm{ab}$ & $5,36 \mathrm{abc}$ & $5,68 \mathrm{ab}$ & $6,28 \mathrm{abc}$ \\
\hline F & $2,84 * *$ & $3,42 * *$ & $13,54 * *$ & $16,51 * *$ & $18,11 *$ & $21,90 * *$ & $13,52 * *$ \\
DMS & 1,05 & 1,28 & 1,06 & 1,08 & 1,22 & 1,17 & 1,71 \\
CV & 16,54 & 17,31 & 11,65 & 10,78 & 11,14 & 9,79 & 13,39 \\
\hline
\end{tabular}

1 Médias seguidas de mesma letra não diferem significativamente entre si pelo teste de Tukey a $1 \%$ de probabilidade.

* significativo pelo teste $\mathrm{F}$ a $5 \%$ de probabilidade.

** significativo pelo teste $\mathrm{F}$ a $1 \%$ de probabilidade.

Planta Daninha, Viçosa-MG, v.18, n.3, p.383-393, 2000 
No que se refere ao grupo de tratamentos de faixas de controle crescentes, foi observado que as plantas de eucalipto que receberam controle inicial de 25 e $50 \mathrm{~cm}$ apresentaram menores diâmetro e altura que aquelas que receberam o controle inicial de 100 e $125 \mathrm{~cm}$ de cada lado da linha de transplante - contraste Y(5) -, de acordo com as Tabelas 5 e 6 . Não se observou diferença em relação a diâmetro e altura das plantas de eucalipto entre tratamentos nos quais se manteve uma faixa de 100 e $125 \mathrm{~cm}$ durante os três meses iniciais (contraste $Y(6))$.

Com relação aos parâmetros de crescimento avaliados na cultura, foi verificada, aos 240 DAT, apenas a tendência de que as faixas fixas de controle de 100, 125 e $150 \mathrm{~cm}$ e as faixas crescentes promoveram maior crescimento em diâmetro das plantas de eucalipto (Tabela 5), quando comparadas com a testemunha não-capinada ("no mato") e as faixas constantes de 25 e $50 \mathrm{~cm}$ de cada lado da linha de transplante. No caso da altura das plantas (Tabela 6), essa tendência foi observada apenas a partir dos 270 DAT, fato que pode ser explicado pelo estiolamento das plantas de eucalipto quando na presença de plantas daninhas, em virtude da competição por luz.

Segundo Pitelli e Marchi (1991), a competição por luz, indubitavelmente, é uma das modalidades de interferência que provoca maior impacto sobre o crescimento do eucalipto, pois restringe a fonte predominante de energia aos processos básicos de recrutamento de elementos e de elaboração de todas as substâncias envolvidas no crescimento do vegetal. Em algumas situações, as plantas daninhas também podem modificar a característica de crescimento das espécies florestais, promovendo estiolamento e proporcionando suporte mecânico. Esta situação permite que a planta ganhe altura rapidamente e reduza o espessamento do caule, tornando-se mais suscetível ao tombamento, quando a comunidade infestante for controlada.

A partir dos 270 DAT, os efeitos das diferentes faixas de controle da comunidade infestante começaram a sobressair, ou seja, as plantas de eucalipto das parcelas de faixas constantes de 100, 125 e $150 \mathrm{~cm}$ (T4, T5 e T6) e das faixas crescentes que iniciaram com 100 e $125 \mathrm{~cm}$ de cada lado da linha de transplante (T11, T12 e T13) mostraram-se com maior diâmetro do caule (Tabela 5) e mais altas (Tabela 6). Já aos 300 DAT as plantas de eucalipto das parcelas que foram mantidas em área total livre da presença de plantas daninhas (T6) mostraramse superiores às dos demais tratamentos, superando-as nas características de crescimento analisadas, o que se manteve até os 390 dias após o transplante, mas não diferiram significativamente das plantas das parcelas de faixas fixas de 100 e $125 \mathrm{~cm}$ (T4 e T5) e das faixas que iniciaram com 100 e $125 \mathrm{~cm}$ de cada lado da linha de transplante (T11, T12 e T13).

No tocante à taxa de crescimento absoluto em diâmetro (Tabela 7), observou-se diferença estatística na última avaliação entre o tratamento que ficou sempre no mato (T1) e o tratamento com faixa crescente de controle de $100 \mathrm{~cm}$ de cada lado da linha de transplante (T11). Pela Tabela 8, observa-se que a taxa de crescimento absoluto em altura mostra diferença significativa a partir de 300 a 330 dias no tratamento com faixa de controle crescente de $125 \mathrm{~cm} \mathrm{e}$ naquele com faixa constante igual a $50 \mathrm{~cm}$.

Em resumo, pelos resultados obtidos nas condições de execução deste trabalho, podese afirmar que a faixa adotada atualmente pela maior parte das empresas florestais, ou seja, a faixa constante de controle de $50 \mathrm{~cm}$ de cada lado da linha de transplante, não foi suficiente para manter as plantas de eucalipto livres da interferência das plantas daninhas. A largura mínima da faixa de controle a ser utilizada, a qual apresentou maior eficácia de controle do capim-braquiária e proporcionou maior velocidade de crescimento e maiores altura e diâmetro das plantas de eucalipto, nas condições deste ensaio, foi a de $100 \mathrm{~cm}$, correspondendo à faixa total de $2,0 \mathrm{~m}$ de largura na linha que não apresentou diferença significativa em relação a outros tratamentos que utilizaram faixas de controle crescentes ou fixas acima de $100 \mathrm{~cm}$. É importante ressaltar que existe a possibilidade de utilizar as faixas fixas de 125 e $150 \mathrm{~cm}$ e as faixas crescentes acompanhando o desenvolvimento radicular das plantas de eucalipto, o que vai depender dos custos e das condições operacionais da empresa, apesar de seu uso não resultar em ganhos significativos no desenvolvimento das plantas de eucalipto, quando comparados à largura mínima de $100 \mathrm{~cm}$. 
Tabela 7 - Efeito das faixas de controle do capim-braquiária sobre a taxa de crescimento absoluto em diâmetro (mm/dia) de plantas de eucalipto, Três Lagoas-MS. 1996/1997

\begin{tabular}{|l|c|c|c|c|c|c|}
\hline \multicolumn{7}{|c|}{ TCA (mm/dia) } \\
\hline \multicolumn{7}{|c|}{ DAT } \\
\hline Trat. & $240-210$ & $270-240$ & $300-270$ & $330-300$ & $360-330$ & $390-360$ \\
\hline T1 & $0,03 \mathrm{a}$ & $0,07 \mathrm{~b}$ & $0,09 \mathrm{a}$ & $0,06 \mathrm{a}$ & $0,09 \mathrm{a}$ & $0,05 \mathrm{~b}$ \\
T2 & $0,12 \mathrm{a}$ & $0,05 \mathrm{~b}$ & $0,58 \mathrm{a}$ & $0,06 \mathrm{a}$ & $0,08 \mathrm{a}$ & $0,13 \mathrm{ab}$ \\
T3 & $0,30 \mathrm{a}$ & $0,14 \mathrm{~b}$ & $0,14 \mathrm{a}$ & $0,11 \mathrm{a}$ & $0,22 \mathrm{a}$ & $0,12 \mathrm{ab}$ \\
T4 & $0,13 \mathrm{a}$ & $0,36 \mathrm{ab}$ & $0,21 \mathrm{a}$ & $0,20 \mathrm{a}$ & $0,17 \mathrm{a}$ & $0,15 \mathrm{ab}$ \\
T5 & $0,23 \mathrm{a}$ & $0,14 \mathrm{~b}$ & $0,34 \mathrm{a}$ & $0,18 \mathrm{a}$ & $0,24 \mathrm{a}$ & $0,13 \mathrm{ab}$ \\
T6 & $0,19 \mathrm{a}$ & $0,59 \mathrm{a}$ & $0,24 \mathrm{a}$ & $0,21 \mathrm{a}$ & $0,24 \mathrm{a}$ & $0,16 \mathrm{ab}$ \\
\hline T7 & $0,08 \mathrm{a}$ & $0,46 \mathrm{ab}$ & $0,28 \mathrm{a}$ & $0,27 \mathrm{a}$ & $0,20 \mathrm{a}$ & $0,15 \mathrm{ab}$ \\
T8 & $0,19 \mathrm{a}$ & $0,12 \mathrm{~b}$ & $0,21 \mathrm{a}$ & $0,29 \mathrm{a}$ & $0,18 \mathrm{a}$ & $0,16 \mathrm{ab}$ \\
T9 & $0,19 \mathrm{a}$ & $0,31 \mathrm{ab}$ & $0,28 \mathrm{a}$ & $0,25 \mathrm{a}$ & $0,23 \mathrm{a}$ & $0,11 \mathrm{ab}$ \\
T10 & $0,13 \mathrm{a}$ & $0,47 \mathrm{a}$ & $0,23 \mathrm{a}$ & $0,17 \mathrm{a}$ & $0,25 \mathrm{a}$ & $0,16 \mathrm{ab}$ \\
T11 & $0,23 \mathrm{a}$ & $0,26 \mathrm{ab}$ & $0,21 \mathrm{a}$ & $0,18 \mathrm{a}$ & $0,27 \mathrm{a}$ & $0,21 \mathrm{a}$ \\
T12 & $0,22 \mathrm{a}$ & $0,24 \mathrm{ab}$ & $0,32 \mathrm{a}$ & $0,19 \mathrm{a}$ & $0,20 \mathrm{a}$ & $0,17 \mathrm{ab}$ \\
T13 & $0,16 \mathrm{a}$ & $0,25 \mathrm{ab}$ & $0,29 \mathrm{a}$ & $0,27 \mathrm{a}$ & $0,22 \mathrm{a}$ & $0,18 \mathrm{ab}$ \\
\hline F & $1,20 \mathrm{~ns}$ & $3,54 * *$ & $1,98 \mathrm{~ns}$ & $2,44 * *$ & $2,08 *$ & $1,88 \mathrm{~ns}$ \\
DMS & 0,32 & 0,44 & 0,30 & 0,24 & 0,20 & 0,14 \\
CV & 76,90 & 66,75 & 53,56 & 51,70 & 40,02 & 37,43 \\
\hline
\end{tabular}

Médias seguidas de mesma letra não diferem significativamente entre si pelo teste de Tukey a 1\% de probabilidade. ns: não-significativo pelo teste $\mathrm{F}$.

* significativo pelo teste $\mathrm{F}$ a $5 \%$ de probabilidade.

** significativo pelo teste $\mathrm{F}$ a $1 \%$ de probabilidade.

Tabela 8 - Efeito das faixas de controle do capim-braquiária sobre a taxa de crescimento absoluto em altura (mm/dia) de plantas de eucalipto, Três Lagoas-MS. 1996/1997

\begin{tabular}{|l|c|c|c|c|c|c|}
\hline \multicolumn{7}{|c|}{ TCA (mm/dia) } \\
\hline \multicolumn{7}{|c|}{ DAT } \\
\hline Trat. & $240-210$ & $270-240$ & $300-270$ & $330-300$ & $360-330$ & $390-360$ \\
\hline T1 & $0,07 \mathrm{a}$ & $0,04 \mathrm{~b}$ & $0,02 \mathrm{a}$ & $0,04 \mathrm{bc}$ & $0,05 \mathrm{~b}$ & $0,06 \mathrm{~cd}$ \\
T2 & $0,07 \mathrm{a}$ & $0,09 \mathrm{~b}$ & $0,05 \mathrm{a}$ & $0,04 \mathrm{bc}$ & $0,03 \mathrm{~b}$ & $0,03 \mathrm{~d}$ \\
T3 & $0,27 \mathrm{a}$ & $0,09 \mathrm{~b}$ & $0,06 \mathrm{a}$ & $0,02 \mathrm{c}$ & $0,26 \mathrm{a}$ & $0,14 \mathrm{abcd}$ \\
T4 & $0,16 \mathrm{a}$ & $0,42 \mathrm{ab}$ & $0,07 \mathrm{a}$ & $0,15 \mathrm{abc}$ & $0,12 \mathrm{ab}$ & $0,15 \mathrm{abcd}$ \\
T5 & $0,20 \mathrm{a}$ & $0,33 \mathrm{ab}$ & $0,16 \mathrm{a}$ & $0,13 \mathrm{abc}$ & $0,16 \mathrm{ab}$ & $0,12 \mathrm{bcd}$ \\
T6 & $0,16 \mathrm{a}$ & $0,52 \mathrm{a}$ & $0,24 \mathrm{a}$ & $0,13 \mathrm{abc}$ & $0,14 \mathrm{ab}$ & $0,18 \mathrm{abc}$ \\
\hline T7 & $0,06 \mathrm{a}$ & $0,26 \mathrm{ab}$ & $0,21 \mathrm{a}$ & $0,18 \mathrm{abc}$ & $0,15 \mathrm{ab}$ & $0,22 \mathrm{ab}$ \\
T8 & $0,23 \mathrm{a}$ & $0,07 \mathrm{~b}$ & $0,23 \mathrm{a}$ & $0,12 \mathrm{abc}$ & $0,16 \mathrm{ab}$ & $0,16 \mathrm{abc}$ \\
T9 & $0,18 \mathrm{a}$ & $0,11 \mathrm{~b}$ & $0,23 \mathrm{a}$ & $0,17 \mathrm{abc}$ & $0,17 \mathrm{ab}$ & $0,16 \mathrm{abc}$ \\
T10 & $0,13 \mathrm{a}$ & $0,07 \mathrm{~b}$ & $0,28 \mathrm{a}$ & $0,16 \mathrm{abc}$ & $0,13 \mathrm{ab}$ & $0,22 \mathrm{a}$ \\
T11 & $0,25 \mathrm{a}$ & $0,21 \mathrm{ab}$ & $0,15 \mathrm{a}$ & $0,19 \mathrm{ab}$ & $0,16 \mathrm{ab}$ & $0,25 \mathrm{a}$ \\
T12 & $0,14 \mathrm{a}$ & $0,31 \mathrm{ab}$ & $0,17 \mathrm{a}$ & $0,19 \mathrm{ab}$ & $0,14 \mathrm{ab}$ & $0,18 \mathrm{ab}$ \\
T13 & $0,17 \mathrm{a}$ & $0,26 \mathrm{ab}$ & $0,14 \mathrm{a}$ & $0,27 \mathrm{a}$ & $0,11 \mathrm{ab}$ & $0,20 \mathrm{ab}$ \\
\hline F & $1,45 \mathrm{~ns}$ & $3,63 * *$ & $1,99 \mathrm{~ns}$ & $4,70 * *$ & $3,20 *$ & $7,10 * *$ \\
DMS & 0,11 & 0,40 & 0,30 & 0,17 & 0,16 & 0,12 \\
CV & 70,47 & 75,35 & 77,97 & 48,42 & 45,57 & 28,98 \\
\hline
\end{tabular}

1 Médias seguidas de mesma letra não diferem significativamente entre si pelo teste de Tukey a $1 \%$ de probabilidade. ns: não-significativo pelo teste $\mathrm{F}$.

* significativo pelo teste $\mathrm{F}$ a $5 \%$ de probabilidade.

**significativo pelo teste $\mathrm{F}$ a $1 \%$ de probabilidade. 


\section{AGRADECIMENTOS}

Ao convênio Champion Papel e Celulose Ltda./ESALQ-USP e à CAPES, pela concessão de bolsas de estudo.

\section{LITERATURA CITADA}

BENINCASA, M.M.R. Análise de crescimento de plantas, noções básicas. Jaboticabal: FUNEP/ FCAV-UNESP, 1988. $41 \mathrm{p}$.

BEZUTTE, A.J., TOLEDO, R.E.B, PITELLI, R.A., ALVES, P.L.C.A. "Efeito da densidade de plantas de Brachiaria decumbens sobre o crescimento inicial de Eucalyptus grandis".In: CONGRESSO BRASILEIRO DA CIÊNCIA DAS PLANTAS DANINHAS, 20, 1995, Florianópolis. Resumos... Florianópolis: 1995. p.272-273.

BRITO, M.A.R. Manejo de plantas daninhas em áreas de reflorestamento. In: CONGRESSO BRASILEIRO DA CIÊNCIA DAS PLANTAS DANINHAS, 20, 1995, Florianópolis. Resumos... Florianópolis: 1995. p.92-95.

CHARUDATTAN, R. Controle biológico de plantas daninhas através de fitopatógenos. In: CURSO INTERNACIONAL SOBRE CONTROLE BIOLÓGICO DE PLANTAS DANINHAS, 1, 1993, Jaboticabal. Curso... Jaboticabal: 1993.

INSTITUTO DE PESQUISA E ESTUDOS FLORESTAIS - IPEF. Tratos culturais, controle de ervas daninhas. Piracicaba: 1976. $7 \mathrm{p}$. (Circular técnica).
MATTEUCCI, S.D., COLMA, A. Methodologia para el estudio de la vegetation. Washington: OEA, 1982. 168p. (Série de Biologia Monografia, 22).

PITELLI, R.A., MARCHI, S.R. Interferência das plantas invasoras nas áreas de reflorestamento. In: SEMINÁRIO TÉCNICO SOBRE PLANTAS DANINHAS E O USO DE HERBICIDAS EM REFLORESTAMENTO, 3, 1991, Belo Horizonte. Anais... Belo Horizonte: 1991. p.1-11.

STAPE, J.L. Definição do período e localização de cobertura de Eucalyptus grandis em função da dinâmica do crescimento radicular. Piracicaba: IPEF, 1990. (Circular técnica, 174)

TOLEDO, R.E.B. Manejo de Brachiaria decumbens Stapf. em área reflorestada com Eucalyptus grandis W. Hill ex Maiden e seu reflexo no crescimento e nutrição mineral da cultura. Jaboticabal: UNESP, 1995. 162p. Monografia (Graduação em Ciências Agrárias e Veterinárias) - Universidade Estadual Paulista “Julio de Mesquita Filho”, 1995.

TOLEDO, R.E.B. Efeitos da faixa de controle e dos períodos de controle e de convivência de Brachiaria decumbens Stapf. no desenvolvimento inicial de plantas de $x$ Eucalyptus urograndis. Piracicaba: ESALQ, 1998. 71p. Dissertação (Mestrado em Fitotecnia). Escola Superior de Agricultura "Luiz de Gueiroz”, Universidade de São Paulo, 1998. 